\title{
SIMULATION OF THE RELATIONSHIP BETWEEN JOINT MOTION AMPLITUDE AND MOTION DAMAGE BASED ON ALGORITHM
}

\author{
SIMULAÇÃO DA RELAÇÃO ENTRE AMPLITUDE DE MOVIMENTO ARTICULARE DANO DEMOVIMENTO \\ BASEADOEM ALGORITMO
}

\section{SIMULACIÓN DE LARELACIÓN ENTRE LA AMPLITUD DEL MOVIMIENTO DE LAS ARTICULACIONES Y EL DAÑO PORMOVIMIENTO BASADO EN ALGORITMO}

Shubo Zhong ${ }^{1}$ D
(Physical Education Professional)

1. Basketball Teaching and Research Department of Jilin Sport University, Changchun, Jilin, China.

\section{Correspondence:}

Shubo Zhong

Basketball Teaching and Research Department of Jilin Sport University, Changchun, Jilin, China. zhangshubo_ccjl@yeah.net

\begin{abstract}
Introduction: With the continuous development of society and the continuous improvement of the economic level, the willingness of Chinese people to participate in sports is also showing an upward trend. However, how to reduce sports damage as much as possible during exercise should be a hot issue of particular concern to athletes in the sports world. Objective: It aimed to discuss the simulation of the relationship between joint motion amplitude (JMA) and motion damage (MD) via a rough set decisionmaking algorithm to avoid MD. Based on the rough set decision algorithm, JMA and MD models were constructed, and a motion data decision table was established. Methods: Joint change parameters and constraint conditions were set, and joint change parameters were analyzed. Moreover, the changing parameters, feature strength, and algorithm partition accuracy of the simulation model were analyzed. Results: The feature strength and the division accuracy of the rough set decision algorithm all showed good accuracy. The model constructed by such a method can well describe the relationship between JMA and MD. Conclusion: The proposed rough set decision algorithm can describe the relationship between JMA and MD scientifically and effectively, which provided reference value for sports. Level of evidence II; Therapeutic studies - investigation of treatment results.
\end{abstract}

Keywords: Range of motion, articular; Movement; Decision trees.

\section{RESUMO}

Introdução: Com o desenvolvimento contínuo da sociedade e a melhoria contínua do nível econômico, a disposição do povo chinês para a prática de esportes também apresenta uma tendência ascendente. No entanto, como reduzir os danos ao esporte tanto quanto possivel durante o exercício deve ser uma questão importante de particular preocupação para os atletas do mundo dos esportes. Objetivo: o objetivo foi discutir a simulação da relação entre amplitude de movimento articular (JMA) e dano de movimento (MD) por meio de um algoritmo de tomada de decisão de conjunto aproximado, para evitar MD. Com base no algoritmo de decisão de conjunto aproximado, os modelos JMA e MD foram construídos e uma tabela de decisão de dados de movimento foi estabelecida. Métodos: os parâmetros de mudança da junta e as condições de restrição foram definidos, e os parâmetros de mudança da junta foram analisados. Além disso, foram analisados os parâmetros de alteração, a força do recurso e a precisão da partição do algoritmo do modelo de simulação. Resultados: A força do recurso e a precisão da divisão do algoritmo de decisão do conjunto aproximado mostraram boa precisão. O modelo construído por esse método pode descrever bem a relação entre JMA e MD. Conclusão: O algoritmo de decisão de conjunto aproximado proposto pode descrever a relação entre JMA e MD de forma científica e eficaz, o que forneceu valor de referência para a área de esportes. Nível de evidência ll; Estudos terapêuticos- investigação dos resultados do tratamento.

Descritor: Amplitude de movimento articular; Movimento; Árvores de decisões.

\section{RESUMEN}

Introducción: Con el desarrollo continuo de la sociedad y la mejora continua del nivel económico, la disposición del pueblo chino a participar en deportes también está mostrando una tendencia al alza. Sin embargo, cómo reducir el daño deportivo tanto como sea posible durante el ejercicio debería ser un tema candente de especial preocupación para los atletas en el mundo del deporte. Objetivo: Su objetivo era discutir la simulación de la relación entre la amplitud del movimiento articular (JMA) y el daño por movimiento (MD) a través de un algoritmo de toma de decisiones de conjunto aproximado, para evitar MD. Con base en el algoritmo de decisión de conjunto aproximado, se construyeron modelos JMA y MD, y se estableció un a tabla de decisión de datos de movimiento. Métodos: Se establecieron los parámetros de cambio de la articulación y las condiciones de restricción, y se analizaron los parámetros de cambio de la articulación. Además, se analizaron los parámetros cambiantes, la fuerza de la característica y la precisión de 
la partición del algoritmo del modelo de simulación. Resultados: La fuerza de la característica y la precisión de la división del algoritmo de decisión de conjunto aproximado mostraron una buena precisión. El modelo construido por tal método puede describir bien la relación entre JMA y MD. Conclusión: El algoritmo de decisión de conjunto aproximado propuesto puede describir la relación entre JMA y MD de manera científica y efectiva, lo que proporcionó un valor de referencia para el campo de los deportes. Nivel de evidencia Il; Estudios terapéuticos- investigación de los resultados del tratamiento.

Descriptores: Rango del movimiento articular; Movimiento; Árboles de decisión.

\section{INTRODUCTION}

With the continuous development of society and the continuous improvement of the economic level, the willingness of Chinese people to participate in sports is also showing an upward trend. However, how to reduce sports damage as much as possible during exercise should be a hot issue of particular concern to athletes in the sports world. In the study of $\mathrm{MD}$, it was found that there is a very close relationship between the joint amplitude and MD. ${ }^{1-3}$ how to scientifically and effectively arrange the load and exercise intensity in training, as well as how to scientifically and effectively grasp the JMA and MD prediction strategies in track and field training, has become an urgent problem in this field..$^{6-8}$

At present, most researchers use ant colony algorithm to improve the relationship between amplitude and damage. The gray neural network algorithm is reformed, and the damage relationship model of the unscented Kalman filter algorithm is established here. However, the disadvantage of this model is that a large amount of data needs to be calculated in the actual operation steps. The time-consuming is relatively large, and the number of iterations is relatively large, which has a certain impact on the authenticity of the data. Decision tree is an effective data classification method. The existence of rough set theory links knowledge and classification very closely. The classification problem of inaccurate and incomplete data can be effectively solved thanks to this mathematical tool that is more in line with human cognition.

\section{METHODS}

In real life adoptions, if there is a completely separable original data set, after this algorithm is adopted, the displayed instance division results are very accurate. However, there is the shortcoming that unknown data can't have good generalization ability. The data collected in this process will also be affected by uncertain factors.Decision trees are classified in attribute selection, one is univariate decision tree, the other is multivariate decision tree. Their complexity determines different attributes. Univariate is determined by the number of leaf nodes and the depth of the tree, and multivariate is determined by the number of branch attributes.

\section{Algorithm proposal}

The algorithm proposed considers two aspects. One is that the influence of noise data reduces overfitting. Another aspect is the degree of complexity of the decision tree. The test data set $C$ is the input, and the decision tree is the output. The algorithm idea is shown as follows. A. Information entropy doesn't go through attribute division, and it is calculated and sorted from small to large.

B. The original data set is divided, each unselected attribute is selected, the number of branches divided into intervals $K$ is counted, and the maximum number of clear intervals max $k$ is calculated.

C. If the number of attributes is set as $j=2$, merge them, and calculate the accuracy of dividing the attribute set into the data set, and the number of intervals is $k$. If the maximum variable precision specifies the interval difference $\operatorname{sub}(k)>$ and the maximum number of attribute branches $(\operatorname{sub}(k)=k-\max k)$, the combined attribute set will be combined as the dividing node, or the single attribute value with the largest $k$ value will be taken.

D. If the value of $k$ in the previous step is 0 , the current node is the attribute with the largest information gain.

E. Each subset performs the previous steps. a. Each subset meets one of the following conditions and ends recursively. All data is divided. b. The decision attribute values in the remaining data sets are different, but the condition attributes are the same. c. The data set is divided but has no attributes.

F. Remove branches. If multiple leaf nodes at the same level have the same attributes, they are classified into the same category and their attributes are merged.

\section{Relationship between JMA and MD}

Correctly expressing and building the relationship model between the two can effectively provide good data support for MD in this field. Therefore, the construction of the model is also very useful, and the estimation of the model relationship is also very important. The state equation of the relationship model between the two is as follows.

$$
a_{k+1}=f\left(a_{k}, u_{k}\right)+w_{k}
$$

$$
b_{k}=g\left(a_{k}, u_{k}\right)+v_{k}
$$

$a$ represents the motion state vector, $u$ is the input variable, and $b$ represents the observable output variable.

In the model, the process error and the observed error are represented by $\omega$ and $v$, respectively.

The motion state of the joint can reflect the motion ability of the joint, and the discrete equation is expressed as follows.

$X_{0} Y_{k}=X_{0} Y_{k-1}{ }^{-}$

Set $X_{0} Y_{0}$ as the initial value of the joint motion state, and $T_{L}$ is the instantaneous joint motion capability.

If the selected MD type is different, equation 4 can be used to express its model.

$b_{k}=K_{0}+K_{1} X_{0} Y_{k}+K_{2} / X_{0} Y_{k}+K_{3} \ln \left(X_{0} Y_{k}\right)+K_{4} \ln \left(1-X_{0} Y_{k}\right)-N_{0} Y T_{L}$

$b_{k}$ represents the instantaneous movement ability. $N_{0}$ represents the instantaneous joint movement ability.

The constants in the motion state are represented by $K_{0}, K_{1}, K_{2}, K_{3}$, and $K_{4}$.

In summary, after the restriction relationship between the two is well established, the relationship model is built successfully. 


\section{Decision table establishment}

For less certain and less complete information, rough set theory can be applied to its analysis. It looks at the target to be studied as a whole system, and uses indistinguishable relations and indistinguishability to obtain similar solutions. The simplified method of rough set attributes is to abstract the motion data first, and then regard it as a data information system. The detailed description is as follows.

First, an information system is given, $\langle W, A \cup B, V, f>, R \subseteq(A \cup B), \forall X \subseteq U$ and the division of domain $W$ independent of the equivalence relation $R$ $\pi(W)=\left\{X_{1}, X_{2}, \ldots X_{n}\right\}$, then the definition of the importance of knowledge $R$ about $X$ is as follows.

$\operatorname{Sig} R(X)=\frac{\left(\mathrm{W}-b_{n} R(X)\right)}{(W)}$

The importance of $R$ on the division of $\pi(\mathrm{W})$ is defined as follows.

$\operatorname{Sig}_{R}(\pi(W))=\frac{\sum_{i-1}^{n}\left(W-b_{n} R\left(X_{1}\right)\right)}{n(W)}$

In a decision table, a division $\pi(W)$ of $W$ can be obtained according to $D$. If knowledge $R$ is a single attribute $a_{i}(i=1,2, \ldots m)$, then, $\operatorname{Sig}_{R}(\pi(W))$ describes the importance of knowledge $R$ about classification.

According to its attribute, classification is made, and the decision tree algorithm of rough set is as follows.

Input: decision table, $\langle W, A \cup B, V, f>, A=\{a 1, a 2, \ldots a n$,$\} ,$ then, a: , ...

Value of decision attribute $V D=\{d 1, d 2, \ldots d n$,$\} ,$ Output: decision tree

1: for the given decision table, $\langle W, A \cup B, V, f\rangle$, calculate the classification of decision attributes $\pi(W)\{X 1, X 2$, $\ldots \mathrm{Xn}$,$\} , and \mathrm{Xi}=[\mathrm{x}] \mathrm{ai}\{\mathrm{i}=1,2, \ldots \mathrm{n}$.

2 : for $(i=1 ; i<=m ; i++)$

$\{$ for $(i=1 ; i<=m ; i++)$

$\{$ ai $(X j)=\{X \mid(\forall x \in W)\} \wedge([X] a i\{\subseteq X j)\}$

$\{$ ai $(X j)=\{X \mid(\forall X \in W)\} \wedge([X]$ ain $X j) \neq \Phi)\}$

bnai $(X j)=a i(X j)-a i(X j)$

$\left.\operatorname{Sigai}(X)=\frac{\left(W-b_{n} R(X)\right)}{(W)}\right\}$

$\left.\operatorname{Sigai}(\pi(\mathrm{W}))=\frac{\sum_{i-1}^{n}\left(\mathrm{~W}-b_{n} \mathrm{R}\left(\mathrm{X}_{1}\right)\right)}{\mathrm{n}(\mathrm{W})}\right\}$

3: calculate aj= argmax $\{$ Sigai $(\pi(W))\}$

4: calculate $W / a j=\{w 1, w 2, \ldots w k\}$

5: for $(i=1 ; i \leq k ; i++)$ If all the examples in $W_{i}$ belong to the same category, then end; otherwise, steps 2 to 5 need to be repeated.

\section{Description of decision tree algorithm based on rough set}

Firstly, for a given decision table, its decision attribute classification is calculated, and the second step is to calculate the classification. Next, $a_{j}$ and $W / a_{j}$ is calculated in turn. If all the examples in $W$ belong to the same category, the process ends. If they don't belong to the same category, continue to repeat the second step (Figure 1).

\section{Decision tree generated by taking outdoor running as an example}

To better understand the decision formed by the rough set decision algorithm, Figure 2 is a schematic diagram of the outdoor running decision tree formed by the rough set decision algorithm.

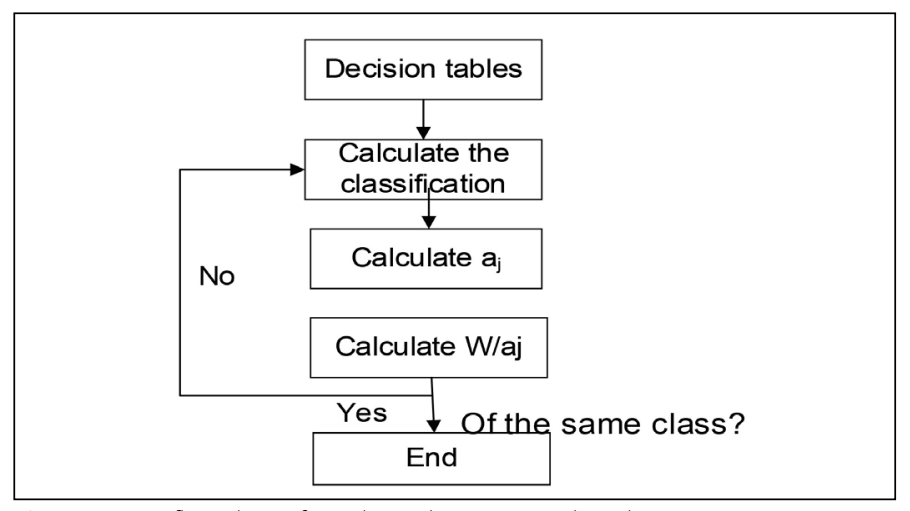

Figure 1. Step flow chart of rough set decision tree algorithm.

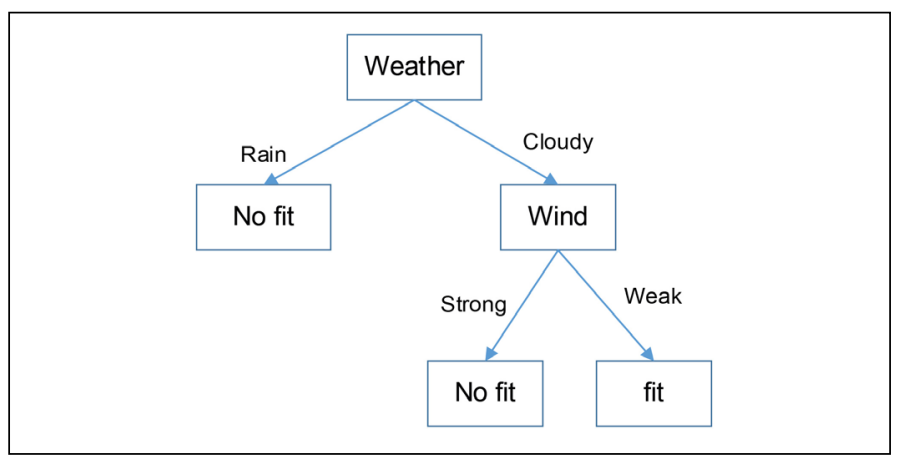

Figure 2. Decision tree for outdoor running.

\section{RESULTS}

\section{Determination of joint change parameters}

The technical movements of an athlete when running was analyzed, and rigid bodies with marked points on the joints of his left ankle, left knee, right ankle, and right knee were selected. The range of punctuation was shown in the dashed box in Figure 3. Two identical unobstructed motion camera capture points in each dotted frame were selected, and then the rigid body was recorded in detail. Furthermore, the specific change parameters were obtained by the rough set decision algorithm step. The variables were assigned to $0.2 \mathrm{~s}, 0.4 \mathrm{~s}, 0.6 \mathrm{~s}, 0.8 \mathrm{~s}, 1.0 \mathrm{~s}, 1.2 \mathrm{~s}, 1.4 \mathrm{~s}$, 1.6 , and $1.8 \mathrm{~s}$, and the result after the record was executed was output.

\section{Time and feature intensity}

Before the angle and strength constraints were determined, the specific parameters needed to be optimized for the linear classification interval to the greatest extent. After processing, the linear relationship between the change parameter and the change was determined, and then the characteristics they showed were analyzed. As time changed, the characteristic intensity curve first increased, then flattened for a period of time, and then showed a decreasing trend (Figure 4).

\section{Algorithm performance comparison}

In Figure 5, the proposed algorithm was compared with the traditional ID3 algorithm in literatures. The partition success rate and accuracy rate of the algorithm proposed were significantly higher than traditional algorithms, showing certain advantages of rough set decision algorithm.

\section{Sports and Tra, Imp}

The meaning of Tra was the instantaneous maximum value of the leg joint exercise intensity, and the meaning of Imp was the transient maximum value. For the same athlete, three kind of sports of different degrees were selected as the research objects. The yield strength of muscles and joints in each exercise was shown in Figure 6. There was a proportional relationship between joint yield strength and muscle resistance. 


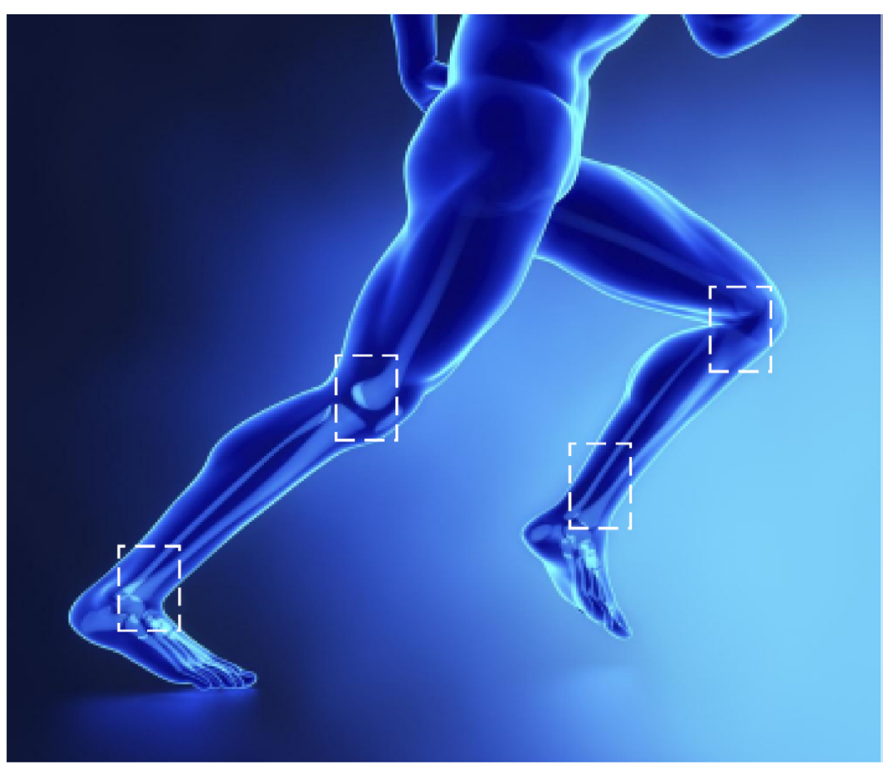

Figure 3. Schematic diagram of taking points under athletes running state.

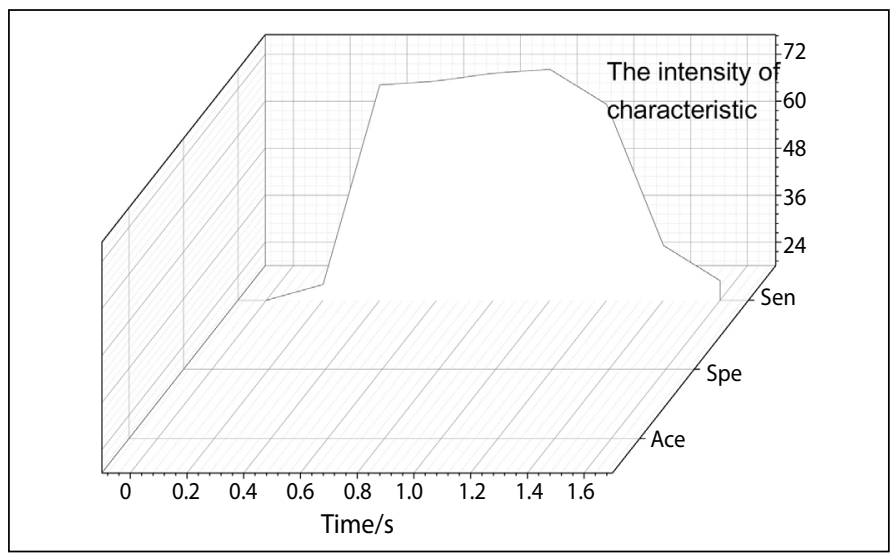

Figure 4. Relationship between time and feature intensity

\section{DISCUSSION}

There are documents that linked MD with exercise intensity. After the joint change parameters and constraints were determined, the simulation model was constructed using intelligent related technology..$^{13}$ The environment design simulation experiment used in the simulation achieved a better description of the relationship between MD and exercise intensity. Rough set decision algorithm was adopted in this research to build the relationship model between JMA and MD, and analyzed the relationship between JMA and injury characteristic strength and joint flexion strength. The results obtained were consistent with expectations, and the accuracy rate obtained was also somewhat higher than that of traditional methods.

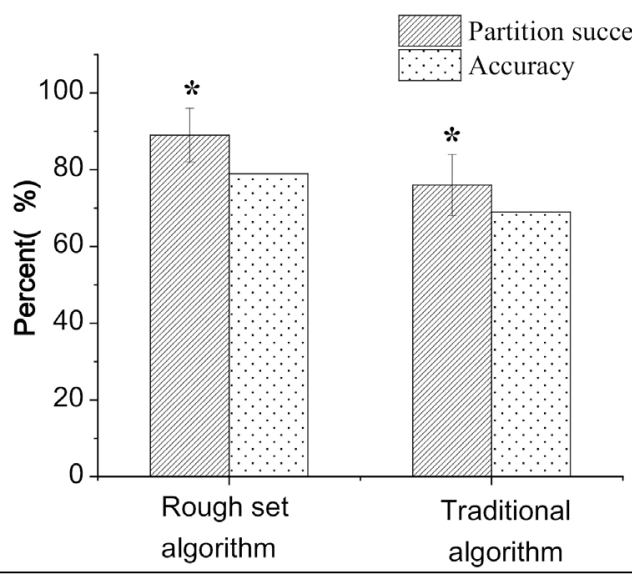

Figure 5. Comparison of accuracy between the algorithm proposed and the traditional ID3 algorithm.

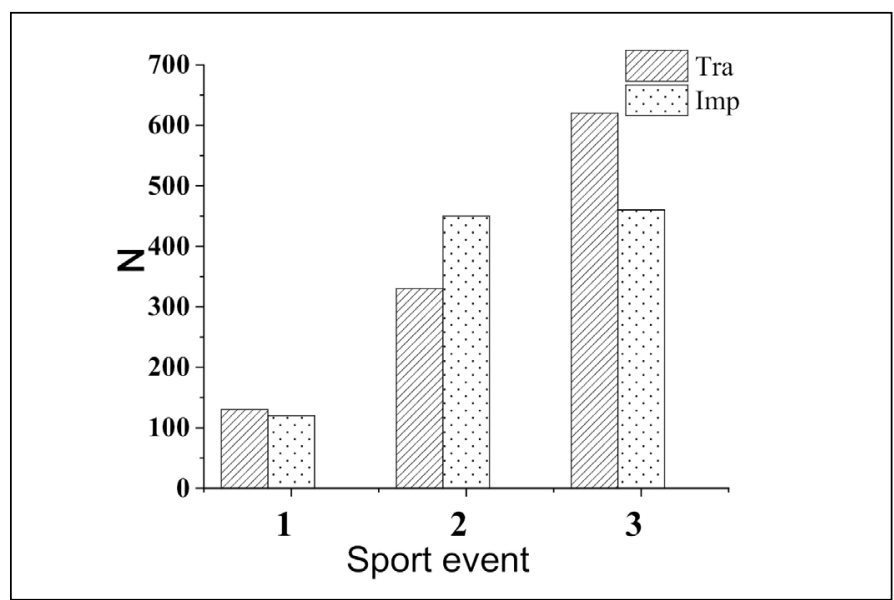

Figure 6. Relationship between sports and Tra and Imp.

\section{CONCLUSION}

The rough set decision algorithm proposed was employed to analyze JMA, injury characteristic strength, and joint flexion strength, so as to better protect the joints and effectively stop the occurrence of joint injuries, aiming at providing a very useful reference basis. It is hoped that the research in this article can help to well alleviate the damage caused by the excessive JMA. The current method can't analyze the influence mechanism of various factors on strengthening the training load intensity. The next step is to solve the problem of large errors in damage analysis.

The author declare no potential conflict of interest related to this article

AUTHORS' CONTRIBUTIONS: Shubo Zhong designed the feature strength and the division accuracy of the rough set decision algorithm, which describe the relationship between JMA and MD scientifically and effectively, which provided reference value for the field of sports.

\section{REFERENCES}

1. Sayed ME, Qubati AGAQA, El-Bably MK. Soft pre-rough sets and its applications in decision making. Math Biosci Eng. 2020;17(5):6045-63.

2. Kirsch A. A unifying computational model of decision making. Cogn Process. 2019;20(2):243-59.

3. Somek M, Hercigonja-Szekeres M. Decision support systems in health care - velocity of apriori algorithm. Stud Health Technol Inform. 2017;244:53-7. .

4. Tseng TL, Huang CC, Fraser K, Ting HW. Rough set based rule induction in decision making using credible classification and preference from medical application perspective. Comput Methods Programs Biomed. 2016;127:273-89.

5. Cruz-Montecinos C, Pérez-Alenda S, Querol F, Cerda M, Maas H. Changes in muscle activity patterns and joint kinematics during gait in hemophilic arthropathy. Front Physiol. 2020;10:1575.

6. Kalo K, Niederer D, Sus R, Sohrabi K, Banzer W, Groß V, et al. The detection of knee joint sounds at defined loads by means of vibroarthrography. Clin Biomech (Bristol, Avon). 2020;74:1-7.

7. Rozzi SL, Lephart SM, Gear WS, Fu FH. Knee joint laxity and neuromuscular characteristics of male and female soccer and basketball players. Am J Sports Med. 1999;27(3):312-9.

8. Konshina AG, Krylov NA, Efremov RG. Cardiotoxins: functional role of local conformational changes. J Chem Inf Model. 2017:57(11):2799-2810.

9. Liu Y, Xie H, Wang L, Tan K. Hyperspectral band selection based on a variable precision neighborhood rough set. Appl Opt. 2016;55(3):462-72.

10. Par OE, Akcapinar Sezer E, Sever H. Clinical decision support systems: from the perspective of small and imbalanced data set. Stud Health Technol Inform. 2019;262:344-7.

11. Sudha M. Evolutionary and neural computing based decision support system for disease diagnosis from clinical data sets in medical practice. J Med Syst. 2017;41(11):178.

12. Gottlieb PK, Vaisbuch Y, Puria S. Human ossicular-joint flexibility transforms the peak amplitude and width of impulsive acoustic stimuli. J Acoust Soc Am. 2018; 143(6):3418.

13. Barrios JM, Romero PE. Decision tree methods for predicting surface roughness in fused deposition modeling parts. Materials (Basel). 2019;12(16):2574. 